\title{
Los/as estudiantes de educación social y trabajo social ante la atención a personas mayores: Intereses profesionales
}

\section{Students of social education and social work in the care of the elderly: professional interests}

\author{
Dapía Conde, M.D.*, Failde Garrido, J.M.* Fernández González, R.* \\ *Universidade de Vigo. Facultad Ciencias Educación
}

\begin{abstract}
Resumen
La gerontología constituye uno de los ámbitos de intervención en auge para los titulados/as en Educación Social y Trabajo Social. Como profesores universitarios encargados de su formación hemos planteado identificar las preferencias vocacionales de estos estudiantes en relación a la intervención con personas mayores. Para ello hemos planteado un estudio cuasi-experimental, descriptivo y transversal, que se materializó en la administración de un cuestionario diseñado ad hoc, a estudiantes ambas titulaciones. Globalmente, los resultados indican un escaso interés de los estudiantes por el colectivo de las personas mayores y un incremento de las preferencias por este grupo de edad en el último curso.
\end{abstract}

Palabras clave: educación social, trabajo social, personas mayores, gerontología]

\begin{abstract}
Gerontology is one of the areas of intervention booming for the graduates in Social Education and Social Work. As university professors in charge of their training, we have set out to identify the vocational preferences of these students in relation to the intervention with the elderly. For this we have Quasi-experimental study, Descriptive and transversal, that materialized in the administration of a questionnaire designed ad hoc, To students both degrees. Overall, the results indicate that there is little interest among students in the group of older people, In the initial stages of his academic stage (first course). However, there is an increase in preferences for this age group in the last school year.

Keywords: social education, social work, older people, gerontology]
\end{abstract}

\section{Introducción}

El envejecimiento poblacional característico de muchas de las sociedades actuales lleva consigo importantes cambios y retos demográficos, económicos sociales y, como no, educativos. Asistimos, pues, a un fenómeno mundial de crecimiento poblacional y mejora de la esperanza de vida de las personas mayores sin precedentes, y que no sólo se limita a los países desarrollados sino también a las áreas y naciones en subdesarrollo donde el crecimiento de la población de personas mayores es también significativo (United Nationts, 2015).

España, al igual que mucho de los países de la Unión Europea ha experimentado un envejecimiento poblacional significativo en las últimas décadas. Es actualmente uno de los países más envejecidos de Europa, y será uno de los más envejecidos en 2050, cuando la población mayor de 60 años supondrá el 40,2 por ciento del total, casi el doble que hoy día, con un 23,4 por ciento de ciudadanos que superan esta edad (Eurostat, 2015).

IMSERSO (2014) plantea unas líneas de actuación que deben orientar las políticas públicas, presentes y futuras, hacia las personas mayores en España. Unas actuaciones dirigidas a promover el envejecimiento activo y la solidaridad entre generaciones, así como apoyar las que desplieguen las entidades, asociaciones de personas mayores y las propias personas mayores. Para ello adoptó las 19 orientaciones que la Unión Europea propuso en la Declaración del Consejo sobre el Año Europeo del Envejecimiento Activo y de la Solidaridad Intergeneracional (2012), que se agrupan en tres apartados - empleo, participación en la sociedad y vida independiente-, y propuso un cuarto referido a la no discriminación, igualdad de oportunidades y atención a situaciones de mayor vulnerabilidad, y constituyen el marco para el desarrollo de las funciones de los educadores/as y trabajadores/as sociales con este colectivo.

Educación Social y Trabajo Social son consideradas profesiones de la intervención social. Según Fantova (2007), podemos denominar intervención social a toda actividad que: se realiza de manera formal u organizada, intentando responder a necesidades sociales, que, específicamente, incide significativamente en la interacción de las personas, aspirando a una legitimación pública o social.

Si analizamos la correspondencia de las funciones que pueden desempeñar en su ejercicio profesional los titulados y tituladas en Educación y Trabajo Social 
(Aneca, 2005 a, b y c) con las líneas de actuación propuestas por Imserso (2014) dirigidas a las personas mayores identificamos un alto paralelismo que, sumado al incremento del porcentaje de personas mayores en relación a la población total, permite identificar este colectivo (y los servicios que se han de satisfacer) como un yacimiento de empleo para estos y estas profesionales de lo social.

Los intereses profesionales se concretan en la formulación explícita que hace una persona de su grado de atracción por una o varias profesiones (Cepero, 2009), es decir, se materializan en una elección profesional. Son el resultado de distintos determinantes -psicológicos y sociológicos, que interactúan entre sí-: autoconcepto, madurez vocacional, carrera profesional deseada.... Por lo tanto, son la consecuencia de un proceso que se va construyendo a lo largo de la vida a partir de una historia de experiencias y pequeñas decisiones, donde se han tenido ensayos previos, y se valida a través de la experiencia histórica del sujeto.

No obstante, este proceso no está exento de una pequeña contradicción; la ilusión profesional o representación que hace el/la joven de un oficio o profesión antes de haber podido tener contacto efectivo con él, por lo que es aconsejable que mientras esté realizando sus estudios tenga un contacto de primera mano con su realidad profesional.

Como profesores universitarios encargados de su formación nos ha parecido de interés conocer sus preferencias vocacionales. En este sentido, la presente comunicación tiene como objetivos: i) identificar los intereses profesionales de los estudiantes de ambas titulaciones en relación al ámbito de intervención con personas mayores; ii) analizar la evolución a lo largo del ciclo educativo (primer y último curso); y iii) determinar si existen diferencias en función de la titulación.

\section{Método}

\section{Participantes}

Participaron en el estudio un total de 175 participantes, estudiantes de $1^{\circ}$ y $4^{\circ}$ curso de los grados de Educación Social y Trabajo Social de la Facultad de Ciencias de la Educación (Universidad de Vigo, campus de Ourense), correspondiendo el $43.4 \%$ a la primera titulación y el $56.6 \%$ a la segunda. El perfil del alumnado participante quedó definido por una mujer $(86.3 \%$ de mujeres frente a $13.7 \%$ de varones), con una media de edad de 21.32 años $(\mathrm{Sx}=3.63)$, cuya vía principal de acceso a la universidad fue a través del PAU (75.9\%).

\section{Instrumentos}

La recogida la información se realizó mediante un cuestionario diseñado ad hoc. Para conocer sus expectativas laborales, se emplearon como variables de estudio el grupo de edad con el que le gustaría trabajar y la elección del grupo de edad de personas mayores como primera preferencia laboral; además se han incluido datos sociodemográficos (edad, sexo...), así como vía de acceso a la universidad.

\section{Procedimiento}

Todos los y las estudiantes de primer y último curso del grado de Educación Social y Trabajo Social fueron invitados a participar, de forma libre y voluntaria, en este estudio, cubriendo un cuestionario anónimo que se administró en las propias aulas por la misma persona, siendo informados de la finalidad de la investigación.

\section{Diseño}

Hemos planteado un estudio cuasi-experimental, descriptivo y transversal, mediante encuestas.

\section{Análisis de datos}

Para el análisis de datos se recurrió a la utilización de técnicas de estadística descriptiva univariada, medias y desviaciones típicas, frecuencias y porcentajes, así como contrastes analíticos mediante la prueba de chi cuadrado. Los datos fueron analizados mediante el programa estadístico SPSS, versión 24 para Windows.

\section{Resultados}

En relación al primer objetivo, los resultados indican un escaso interés de los estudiantes de Educación Social y Trabajo Social, considerados conjuntamente, por el colectivo de las personas mayores como ámbito de intervención; solamente el $23.4 \%$ elige al colectivo de personas mayores entre los grupos de edad con los que le gustaría trabajar y el $22.3 \%$ lo sitúa como primera opción (ver figura 1).

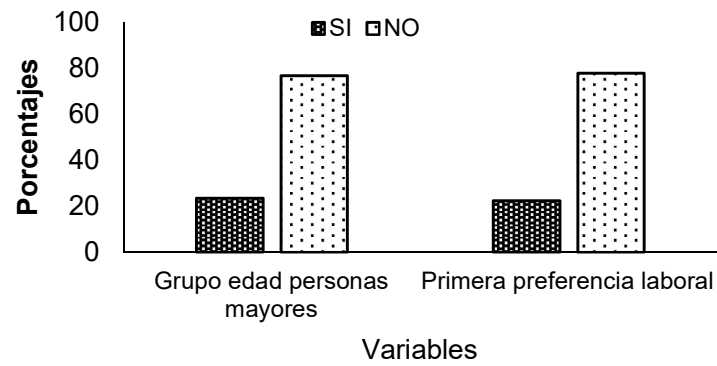

Figura 1. Intereses personas mayores. Porcentajes

Si los intereses hacia el colectivo de personas mayores, se analizan atendiendo a la titulación, no se manifiesta asociación entre preferencias por este grupo etario y la titulación cursada (ver tabla 1). Por el contrario, cuando los intereses se analizan atendiendo al curso, tabla 2 , se constata mayor preferencia en $4^{\circ}$ curso que en primero, tanto respecto al grupo con el que le gustaría trabajar $\left(\mathrm{X}^{2}=5.44 ; \mathrm{p}<.017\right)$ como en la primera elección laboral $\left(\mathrm{X}^{2}=11.567 ; \mathrm{p}<.001\right)$, llegando incluso a duplicarse las preferencias. 
Tabla 1.

Intereses personas mayores, por titulación

\begin{tabular}{lcccc}
\hline & $\begin{array}{c}\text { Edu. } \\
\text { Social }\end{array}$ & $\begin{array}{r}\text { Trabajo } \\
\text { Social }\end{array}$ & $\mathrm{X}^{2}$ & Sig \\
\hline $\begin{array}{l}\text { Grupo edad personas } \\
\text { mayores }\end{array}$ & 22.4 & 24.2 & 0.84 & 0.458 \\
$\begin{array}{l}\text { Primera preferencia } \\
\text { laboral }\end{array}$ & 17.1 & 26.3 & 2.08 & 0.103 \\
\hline
\end{tabular}

Tabla 2.

Intereses personas mayores, por curso

\begin{tabular}{lcccc}
\hline & $\begin{array}{c}\text { Primer } \\
\text { curso }\end{array}$ & $\begin{array}{c}\text { Cuarto } \\
\text { curso }\end{array}$ & $\mathrm{X}^{2}$ & Sig \\
\hline $\begin{array}{l}\text { Grupo edad personas } \\
\text { mayores }\end{array}$ & 18.1 & 33.9 & 5.44 & 0.017 \\
$\begin{array}{l}\text { Primera preferencia } \\
\text { laboral }\end{array}$ & 14.7 & 37.3 & 11.57 & 0.001 \\
\hline
\end{tabular}

Cuando se segmentaron los datos por titulación, tabla 3 y 4, las diferencias por cursos solamente se dan en el Grado de Trabajo Social $\left(\mathrm{X}^{2}=5.331 ; \mathrm{p}<.020 ; \mathrm{X}^{2}=7.993\right.$; $\mathrm{p}<.005$, respectivamente para cada una de las variables estudiadas); para Educación Social, aunque se incrementa el interés, en la elección del grupo de personas mayores como grupo con el que le gustaría trabajar y en elegir este colectivo como primera preferencia laboral.

Tabla 3.

Intereses personas mayores, por curso. Educación Social

\begin{tabular}{lcccc}
\hline & $\begin{array}{c}\text { Primer } \\
\text { curso }\end{array}$ & $\begin{array}{c}\text { Cuarto } \\
\text { curso }\end{array}$ & $\mathrm{X}^{2}$ & Sig \\
\hline $\begin{array}{l}\text { Grupo edad personas } \\
\text { mayores }\end{array}$ & 20.0 & 28.6 & 0.64 & 0.539 \\
$\begin{array}{l}\text { Primera preferencia } \\
\text { laboral }\end{array}$ & 12.7 & 28.6 & 2.69 & 0.169 \\
\hline
\end{tabular}

Tabla 4.

Intereses personas mayores, por curso. Trabajo Social

\begin{tabular}{lcccc}
\hline & $\begin{array}{c}\text { Primer } \\
\text { curso }\end{array}$ & $\begin{array}{c}\text { Cuarto } \\
\text { curso }\end{array}$ & $\mathrm{X}^{2}$ & Sig \\
\hline $\begin{array}{l}\text { Grupo edad personas } \\
\text { mayores }\end{array}$ & 16.4 & 36.8 & 5.33 & 0.020 \\
$\begin{array}{l}\text { Primera preferencia } \\
\text { laboral }\end{array}$ & 16.4 & 42.1 & 7.80 & 0.005 \\
\hline
\end{tabular}

\section{Conclusión}

Los resultados de este estudio se concretan en las siguientes conclusiones:

- El interés de los estudiantes de Educación Social y Trabajo social de la Universidad de Vigo hacia el colectivo de personas mayores, como ámbito de intervención, es bajo en las fases iniciales de sus estudios; no detectándose diferencias estadísticamente significativas entre ambas titulaciones.

- En las etapas finales de estudios, sin embargo, se incrementa significativamente el interés por trabajar con este colectivos, tanto cuando consideramos su elección como primera opción profesional, como cuando consideramos los ámbitos de elección preferidos. Sin embargo, solamente se detectaron diferencias significativas entre primer y cuarto curso en la titulación de Trabajo Social

En síntesis, los resultados reflejan el bajo interés de los estudiantes del ámbito social por las personas mayores, lo que constituye para el profesorado una preocupación que nos lleva a replantear actuaciones para mejorar la perspectiva gerontológica de nuestro alumnado, habida cuenta de que el colectivo de personas mayores se configura como uno de los sectores profesionales más importantes de inserción laboral para ambas titulaciones, de modo espacial para la Educación Social.

\section{Referencias}

Aneca (2005a). Libro Blanco del Título de Grado en Pedagogía y Educación Social (I). Madrid: Autor.

Aneca (2005b). Libro Blanco del Título de Grado en Pedagogía y Educación Social (II). Madrid: Autor.

Aneca (2005c). Libro Blanco del Título de Grado en Trabajo Social. Madrid: Autor.

Cepero, A.B. (2009). Las preferencias profesionales y vocacionales del alumnado de secundaria y formación profesional especifica. Tesis doctoral. Universidad de Granada, Facultad de Ciencias de la Educación.

Eurostat (2015) La mortalidad y las estadisticas de esperanza de vida. Extraído de:

http://translate.googleusercontent.com/translate_c?dep th $=1 \& \mathrm{hl}=$ es \&prev=search\&rurl=translate.google.es\& $\mathrm{sl}=\mathrm{en} \& \mathrm{u}=\mathrm{http}: / /$ ec.europa.eu/eurostat/statistics-explai ned/ index.php/Mortality_and_life_expectancy_statistics\& usg=ALkJrhhL5FEIvZJkUEWXXd6K7-aLYrbovQ

Fantova, F. (2007). Repensando la intervención social. Documentación Social, 147, 183-198.

UNited Nations (2015). World Population Prospects: The 2015 Revision, Key Findings and Advance Tables. Nueva York: United Nations. Department of Economic and Social Affairs, Population Division. 